\title{
Outcomes of young children hospitalized with acute wheezing
}

\author{
Sasawan Chinratanapisit, ${ }^{1}$ Paskorn Sritipsukho, ${ }^{2,3}$ Araya Satdhabudha, ${ }^{4}$ Khlongtip Matchimmadamrong, ${ }^{5}$ itladda Deerojanawong, ${ }^{6}$ \\ Narissara Suratannon, ${ }^{7}$ Pantipa Chatchatee ${ }^{7}$
}

\begin{abstract}
Background: Wheezing in preschool children is a common symptom.

Objective: The study aimed to determine an incidence of recurrent wheezing among young children who had been hospitalized with acute wheezing after 12 months. Factors associated with recurrent wheezing were explored.

Methods: A longitudinal study was conducted among 236 children, aged between 6 months and 5 years, who were hospitalized with acute wheezing in 4 hospitals located in Bangkok and adjacent provinces, Thailand. Demographics, house environments and clinical characteristic data were collected at entry. Serum specific IgE levels against common food and inhalant allergens and serum 25-hydroxyvitamin D (25OHD) concentrations were measured.
\end{abstract}

Results: At entry, the mean age was 24.4 months ( $\mathrm{SD}=15.7$ months). Of 236 hospitalized children with acute wheezing, ninety-four cases (39.8\%) were the first wheezing episode of life. By laboratory results, 197 (83.5\%) and 56 (23.7\%) children were atopic and had vitamin D insufficiency respectively. There were 195 cases completely followed for 12 months. One-year risk of emergency visits and hospitalization due to recurrent wheezing were $49.7 \%$ and $23.1 \%$ respectively. By multivariable analysis, being the second born child or more, vitamin D insufficiency, "ever wheeze", and allergic rhinitis were significantly associated with recurrent wheezing within 12 months with adjusted odds ratios of 2.5 (95\% confidence interval: 1.3-5.3), 2.3 (95\% confidence interval: 1.1-4.4), 1.9 (95\% confidence interval: 1.2-3.5), and 1.6 (95\% confidence interval: 1.3-2.9) respectively.

Conclusion: Being the second born child or more, vitamin D insufficiency, ever wheeze, and allergic rhinitis were significant risks of recurrent wheezing.

Key words: incidence, recurrent wheeze, preschool, hospitalization, risk factors

\section{From:}

${ }^{1}$ Department of Pediatrics, Bhumibol Adulyadej Hospital, Thailand

${ }^{2}$ Division of Allergy and Immunology, Department of Pediatrics,

Faculty of Medicine, Thammasat University

Center of Excellence in Applied Epidemiology, Thammasat University, Thailand

${ }^{4}$ Division of Respiratory disease, Department of Pediatrics,

Faculty of Medicine, Thammasat University, Thailand

Department of Pediatrics, Saraburi Hospital, Saraburi, Thailand

${ }^{6}$ Division of Respiratory disease and intensive care, Department of Pediatrics, Faculty of Medicine, Chulalongkorn University,

King Chulalongkorn Memorial Hospital, the Thai Red Cross Society, Bangkok, Thailand

Pediatric Allergy \& Clinical Immunology Research Unit,

Division of Allergy and Immunology, Department of Pediatrics, Faculty of Medicine, Chulalongkorn University, King Chulalongkorn Memorial Hospital, the Thai Red Cross Society, Bangkok, Thailand

Corresponding author:

Paskorn Sritipsukho

Center of Excellence in Applied Epidemiology, Thammasat University (Rangsit Campus)

99 Paholyothin Rd, Khlong Luong, Pathum Thani, 12120, Thailand

E-mail: paskorn100@yahoo.com

\section{Introduction}

Wheezing is the problem that is often found in children, especially the small ones. It's most often found in the first year of life. ${ }^{1-2}$ Approximately one third of children had had wheezing at least once by the time they reached 3 years of age. Half of the children had cumulative wheezing during the first 6 years. ${ }^{3-4}$ Recurrent wheeze in preschool children has various prognoses. The management of wheezing in young children is associated with many challenges. The diagnosis could be difficult as wheezing can occur in this age without asthma and confirmatory lung function tests are difficult to perform. ${ }^{5}$ Genetic with environmental factors might be responsible for childhood pattern of wheezing. Also, many medications for asthma are poorly studied in very young children. From the birth cohort study, ${ }^{4}$ some children had only transient wheezing, which related to viral infection but would not develop into asthma at school. However, the classification of patients by retrospective wheezing phenotype pattern as transient wheeze or persistent wheeze cannot be used in clinical practice, since 
it is retrospective categorization. This study aimed to determine the incidence of recurrent wheezing after 12 months among young children who were hospitalized with acute wheezing. Factors associated with recurrent wheezing were explored.

\section{Material and Methods}

A longitudinal study was conducted among 236 preschool children who were hospitalized with acute wheezing in four hospitals including Bhumibol Adulyadej Hospital, King Chulalongkorn Memorial Hospital, Saraburi Hospital, and Thammasat University Hospital. They were recruited during July 2014 to June 2015 with ages of 6 months to 5 years. The first or recurrent wheezing episodes were eligible for the study but would be excluded from the study if they had onset of wheezing in perinatal period or chronic diseases including congenital heart diseases, bronchopulmonary dysplasia, structural airway malformation, acquired immune deficiency syndrome (AIDs), and cerebral palsy. The informed consents were obtained from their caregivers.

At admission, demographic and household characteristic data were collected by parental-administered questionnaire. Serum samples of the participants at entry were measured for specific IgE levels by ImmunoCAP (Phadia, Uppsala, Sweden) to determine sensitization to common allergens including cow's milk, egg white, dust mite, cockroach, dog, cat and Bermuda grass. Atopy was defined as having at least one allergen sensitization by the cutoff value of $0.35 \mathrm{kUA} / \mathrm{L}$. Serum samples at entry were assessed for 25-hydroxy vitamin D (25OHD) concentrations by enzyme-linked immunosorbent assay (ELISA).
Vitamin D insufficiency was defined by the serum 25OHD levels of $<30 \mathrm{ng} / \mathrm{ml}$. Eighty children were available to obtain nasopharyngeal suction to identify influenza virus, respiratory syncytial virus (RSV), rhinovirus and enterovirus68 using realtime polymerase chain reaction (RT-PCR).

The participants were followed every 4 months for 12 months to record the outcomes including hospitalizations and emergency visits due to recurrent wheezing. The study was approved by the human ethics committees of all four hospitals.

The study required the sample size of 236 to determine estimated incidence of recurrent wheezing at 12 months of 30 percent. The margin errors of the estimation of 6 percent with the type one errors of 0.05 were determined. Exploratory analysis by multiple logistic regressions was used to determine independent factors associated with recurrent wheeze during 12 months of follow-up, presented with adjusted odds ratio and $95 \%$ confidence interval $(95 \% \mathrm{CI})$. Subgroup analysis was performed to assess an association between rhinovirus infection and recurrent wheezing during 12 months of follow-up presented with risk ratio.

\section{Results}

At entry, the mean age of the participants was 24.4 months (SD $=15.7$ months) with 148 boys $(62.7 \%)$. Of 236 hospitalized children, ninety-four cases $(39.8 \%)$ were the first wheezing episode of life. Paternal and maternal history of asthma was 17.4 and 13.6 percent respectively. The highest prevalence of sensitization was to cow's milk (50.8\%), followed by egg white $(35.6 \%)$. Patients' characteristics stratified by history of wheezing at admission were presented in Table $\mathbf{1}$.

Table 1. Patients' characteristic at entry, stratified by history of wheezing at admission

\begin{tabular}{|c|c|c|c|c|c|c|}
\hline \multirow{2}{*}{ Characteristics } & \multicolumn{2}{|c|}{ Total } & \multicolumn{2}{|c|}{$\begin{array}{l}\text { "The first wheeze" } \\
\text { group }\end{array}$} & \multicolumn{2}{|c|}{$\begin{array}{l}\text { "Ever wheeze" } \\
\text { group }\end{array}$} \\
\hline & $N=236$ & $\%$ & $\mathbf{N}=94$ & $\%$ & $\mathrm{~N}=142$ & $\%$ \\
\hline \multicolumn{7}{|l|}{ Parental academic degrees } \\
\hline Primary school & 23 & 9.7 & 10 & 10.6 & 13 & 9.2 \\
\hline Secondary school & 132 & 55.9 & 57 & 60.6 & 75 & 52.8 \\
\hline Bachelor degrees or higher & 81 & 34.3 & 27 & 28.8 & 54 & 38.0 \\
\hline Paternal asthma & 41 & 17.4 & 13 & 13.8 & 23 & 16.2 \\
\hline Maternal asthma & 32 & 13.6 & 10 & 10.6 & 18 & 12.7 \\
\hline Current passive smoking in household & 106 & 44.9 & 48 & 51.1 & 58 & 40.8 \\
\hline Boys & 148 & 62.7 & 56 & 59.6 & 92 & 64.8 \\
\hline \multicolumn{7}{|l|}{ Age (months) } \\
\hline $6-12$ & 61 & 25.8 & 26 & 27.7 & 35 & 24.6 \\
\hline $12-24$ & 66 & 28.0 & 25 & 26.6 & 41 & 28.9 \\
\hline $24-36$ & 48 & 20.3 & 18 & 19.1 & 30 & 21.1 \\
\hline $36-60$ & 61 & 25.8 & 25 & 26.6 & 36 & 25.4 \\
\hline The second born child or more & 121 & 51.3 & 46 & 48.9 & 75 & 52.8 \\
\hline Allergic rhinitis & 48 & 20.3 & 16 & 17.0 & 32 & 22.5 \\
\hline
\end{tabular}


Table 1. (Continued)

\begin{tabular}{|c|c|c|c|c|c|c|}
\hline \multirow{2}{*}{ Characteristics } & \multicolumn{2}{|c|}{ Total } & \multicolumn{2}{|c|}{$\begin{array}{l}\text { "The first wheeze" } \\
\text { group }\end{array}$} & \multicolumn{2}{|c|}{$\begin{array}{l}\text { "Ever wheeze" } \\
\text { group }\end{array}$} \\
\hline & $N=236$ & $\%$ & $\mathbf{N}=94$ & $\%$ & $N=142$ & $\%$ \\
\hline Atopic dermatitis & 37 & 15.7 & 14 & 14.9 & 23 & 16.2 \\
\hline \multicolumn{7}{|l|}{ Allergen sensitization (> $0.35 \mathrm{kUA} / \mathrm{L})$} \\
\hline cow's milk & 120 & 50.8 & 42 & 44.7 & 78 & 54.9 \\
\hline egg white & 84 & 35.6 & 32 & 34.0 & 52 & 36.6 \\
\hline $\operatorname{dog}$ & 47 & 19.9 & 19 & 20.2 & 28 & 19.7 \\
\hline cat & 33 & 14.0 & 14 & 14.9 & 19 & 13.4 \\
\hline dust mite & 77 & 32.6 & 27 & 28.7 & 50 & 35.2 \\
\hline cockroach & 45 & 19.1 & 15 & 16.0 & 30 & 21.1 \\
\hline Bermuda grass & 37 & 15.7 & 14 & 14.9 & 23 & 16.2 \\
\hline Atopy (> one allergen sensitization) & 197 & 83.5 & 75 & 79.8 & 122 & 85.9 \\
\hline Blood Eosinophil > 4\% & 11 & 4.7 & 4 & 4.3 & 7 & 4.9 \\
\hline Vitamin D insufficiency $(<30 \mathrm{ng} / \mathrm{ml}, \mathrm{N}=225)$ & 56 & 23.7 & $19 / 89$ & 21.3 & $37 / 136$ & 27.2 \\
\hline Viral antigen assay ${ }^{*}(\mathrm{~N}=80)$ & & & $(\mathrm{N}=33)$ & & $(\mathrm{N}=47)$ & \\
\hline Not detected & 32 & 40.0 & 14 & 42.4 & 18 & 38.3 \\
\hline Rhinovirus & 36 & 45.0 & 15 & 45.5 & 21 & 44.7 \\
\hline RSV & 8 & 10.0 & 3 & 9.1 & 5 & 10.6 \\
\hline Enterovirus68 & 4 & 5.0 & 1 & 3.0 & 3 & 6.4 \\
\hline Influenza & 0 & 0 & 0 & 0 & 0 & 0 \\
\hline
\end{tabular}

${ }^{*}$ Nasopharyngeal specimen by real-time PCR

Table 2. Patients' characteristics between completed follow-up and loss to follow-up group

\begin{tabular}{|lccccc} 
& \multicolumn{2}{c}{ Completed follow-up } & \multicolumn{2}{c}{ Loss to follow-up } & \\
\cline { 2 - 4 } \multicolumn{1}{c}{ Characteristics } & $\mathbf{N}=\mathbf{1 9 5}$ & $\%$ & $\mathbf{N}=\mathbf{4 1}$ & $\%$ & p-value \\
\hline Parental academic degrees & & & & & 0.564 \\
\hline Primary school & 19 & 9.7 & 4 & 9.8 & \\
\hline Secondary school & 112 & 57.4 & 20 & 48.8 & \\
\hline Bachelor degrees or higher & 64 & 32.8 & 17 & 41.5 & \\
\hline Paternal asthma & 33 & 16.9 & 8 & 19.5 & 0.656 \\
\hline Maternal asthma & 26 & 13.3 & 6 & 14.6 & 0.804 \\
\hline Current passive smoking in household & 85 & 43.6 & 21 & 51.2 & 0.392 \\
\hline Boys & 120 & 61.5 & 28 & 68.3 & 0.480 \\
\hline Mean age at entry (months) & $24.8 \pm 15.8$ & $24.1 \pm 16.9$ & 0.791 \\
\hline The second born child or more & 99 & 50.8 & 22 & 53.7 & 0.864 \\
\hline Allergic rhinitis & 40 & 20.5 & 8 & 19.5 & 0.885 \\
\hline Atopic dermatitis & 29 & 14.9 & 8 & 19.5 & 0.480 \\
\hline
\end{tabular}


Table 3. Incidence of recurrent wheezing during the follow up period of 12 months

\begin{tabular}{|c|c|c|c|c|}
\hline & \multicolumn{4}{|c|}{ Recurrent wheezing within 12-months follow-up } \\
\hline & \multicolumn{2}{|c|}{ Emergency visits } & \multicolumn{2}{|c|}{ Hospitalization } \\
\hline & $\mathbf{N}$ & Incidence risk (95\%CI) & $\mathbf{N}$ & Incidence risk $(95 \% \mathrm{CI})$ \\
\hline Total $(\mathrm{N}=195)$ & 97 & $49.7 \%(42.5 \%-57.0 \%)$ & 45 & $23.1 \%(17.4 \%-29.6 \%)$ \\
\hline The first wheeze episode $(\mathrm{N}=78)$ & 33 & $42.3 \%(31.2 \%-54.0 \%)$ & 15 & $19.5 \%(11.3 \%-30.1 \%)$ \\
\hline History of "ever wheeze" ( $\mathrm{N}=117)$ & 64 & $54.7 \%(45.2 \%-64.0 \%)$ & 30 & $25.7 \%(18.0 \%-34.5 \%)$ \\
\hline
\end{tabular}

There were 195 cases completely followed for 12 months. Characteristics of patients who were loss to follow-up was comparable to the completed follow-up group detailed in Table 2. One-year risk of emergency visits and hospitalization due to recurrent wheeze were $49.7 \%$ and $23.1 \%$ respectively, presented in Table 3. Inhaled corticosteroids and leukotriene receptor antagonist (LTRA) were prescribed, at least once from hospital visits, during follow-up period of 12 months for $33.3 \%$ and $23.1 \%$ respectively.

By multiple logistic regression model, being the second child or more, history of previous wheezing, allergic rhinitis, vitamin $\mathrm{D}$ insufficiency were significantly associated with recurrent wheezing during a follow-up period of 12 months described in Table 4.

Table 4. Risk factors of emergency visits due to recurrent wheezing during 12 months of follow-up

\begin{tabular}{lcc}
\hline \multicolumn{1}{c}{ Risk factors } & Adjusted Odds ratio (95\% CI) & P-value \\
\hline The second born child or more & $2.5(1.3-5.3)$ & $0.007^{\star}$ \\
\hline Vitamin D insufficiency $(<30 \mathrm{ng} / \mathrm{ml})$ & $2.3(1.1-4.4)$ & $0.046^{\star}$ \\
\hline "Ever wheeze" before admission & $1.9(1.2-3.5)$ & $0.041^{*}$ \\
\hline Allergic rhinitis & $1.6(1.3-2.9)$ & $0.035^{*}$ \\
\hline Atopic dermatitis & $1.7(0.87-3.47)$ & 0.231 \\
\hline Boy & $0.97(0.33-1.59)$ & 0.471 \\
\hline Age more than 2 years & $0.95(0.71-1.29)$ & 0.740 \\
\hline Atopy ${ }^{*}$ & $0.97(0.24-3.21)$ & 0.819 \\
\hline Paternal asthma & $1.04(0.89-1.33)$ & 0.404 \\
\hline Maternal asthma & $1.06(0.74-1.24)$ & 0.542 \\
\hline Current passive smoking in household & $1.31(0.55-2.81)$ & 0.649 \\
\hline Blood eosinophilia $(>4 \%)$ & $0.85(0.14-4.73)$ & 0.791 \\
\hline Prescribing inhaled corticosteroids & $1.2(0.6-3.1)$ & 0.152 \\
\hline Prescribing LTRA & $0.9(0.3-3.9)$ & 0.481 \\
\hline
\end{tabular}

* Statistical significance at the level of 0.05 by Wald tests of logistic regression model

${ }^{* *}>$ one allergen sensitization

Table 5. Association between rhinovirus infection at admission and recurrent wheeze during 12 months of follow-up

\begin{tabular}{|c|c|c|c|c|}
\hline Rhinovirus infection & $\begin{array}{l}\text { No recurrent } \\
\text { wheezing }^{\star}\end{array}$ & $\begin{array}{l}\text { Recurrent } \\
\text { wheezing* }\end{array}$ & $\begin{array}{c}\text { Risk ratio } \\
(95 \% \text { Confidence interval) }\end{array}$ & P-value \\
\hline \multicolumn{5}{|c|}{ "The first wheeze at admission" group } \\
\hline No Rhinovirus & $11(84.6 \%)$ & $2(15.4 \%)$ & - & \\
\hline Rhinovirus & $5(50.0 \%)$ & $5(50.0 \%)$ & $3.3(0.8-13.4)$ & 0.074 \\
\hline \multicolumn{5}{|l|}{ "Ever wheeze at admission" group } \\
\hline No Rhinovirus & $7(36.8 \%)$ & $12(63.2 \%)$ & - & \\
\hline Rhinovirus & $6(35.3 \%)$ & $11(64.7 \%)$ & $1.0(0.6-1.7)$ & 0.923 \\
\hline
\end{tabular}

${ }^{\star}$ Emergency visits due to recurrent wheezing 
According to nasopharyngeal suction for viral study in 80 children, there were 48 cases (60\%) positive for viral PCR and the most prevalent viral infection was rhinovirus (40\%). Rhinovirus increased the risk of recurrent wheeze during oneyear follow-up period among hospitalized children who had the first wheezing episode at admission with the risk ratio of 3.3 (95\% CI: 0.8-13.4), but not reach statistical significant level presented in Table 5.

\section{Discussion}

This is a prospective study that justifies the ability to identify associated factors for recurrent wheezing in hospitalized preschool children with acute wheezing. However, there are some limitations. First, the study sample size was relatively small, limiting the ability to identify associated factors of recurrent wheezing during 12 months of follow-up. Secondly, the duration of follow-up was until the patient had a recurrent wheeze, with a maximum duration of one year. Thirdly, only 80 children available for viral study of nasopharyngeal suction specimens at admission. Viral infection variable was not included in the multivariable logistic model due to large missing data. Fourthly, this study was conducted in four centers, three of which were tertiary hospitals. This might limit the generalizability of the results.

More than $60 \%$ were boys which are consistent with the epidemiology of general pediatric patients with acute wheezing. ${ }^{6}$ The incidence of recurrent wheezing of $49.7 \%$ in this study corresponds with the previous results of prospective studies $(45.2 \%-61.8 \%))^{7-9}$

In our study, over $80 \%$ of children with acute wheezing had atopy with the highest sensitization to cow's milk protein and egg white. This result is consistent with the sensitization pattern of preschool age children in other studies. ${ }^{10,11}$ Contribution of sensitization to aeroallergens and food allergens to the risk of recurrent wheezing has been reported. ${ }^{12,13}$ But our study did not find an association between allergen sensitization and recurrent wheezing during follow up of 12 months $(p=0.870)$. The effect of atopy on recurrent wheezing might differ depending on phenotype of the study population and the method used determining sensitization. Most participants in our study were preschool children hospitalized with the first wheezing episode or less than 3 wheezing episodes before admission while the Prevention of Asthma in Kids (PEAK) trial ${ }^{12}$ and the study of Guo J, et a ${ }^{13}$ enrolled preschool children with history of more than 3 wheezing episodes. Sensitization reported in the study of Chantawarangul $\mathrm{K}$, et $\mathrm{al}^{7}$ was assessed by skin prick tests while specific serum IgE level was used in our study.

Our study identified significant factors associated with recurrent wheezing during 12 months of follow up in preschool children including being the second born child or more in siblings, "ever wheeze" at admission, vitamin D insufficiency, and allergic rhinitis. Rhinitis was reported as a risk of persistent wheezing in young children by Guo Jing, et $\mathrm{al}^{13}$, especially with aeroallergen sensitization. Other significant factors have been reported to associate with recurrent wheezing including sensitization to allergens (atopy), atopic dermatitis, and blood eosinophilia. ${ }^{7,12-15}$ These factors were not found to have the association with recurrent wheezing during 12 months of follow up in our study. However, epidemiological results varied depending on the study type, study population, definition of exposures and timeframe of follow up.

The second born children or more in siblings were more likely to expose infections from their siblings, resulting in infection induced wheezing more than the first born children. However, Hygiene hypothesis proposed that the risks of asthma reduced by contact with infection in early life. ${ }^{16}$ Reduction of asthma risk was reported with increasing birth order children. ${ }^{17}$ Therefore, longer duration of follow up among these young children was required to identify subsequent asthma development.

Passive smoking in household did not significantly increase the risk of recurrent wheezing in our study, similar to the report from Chantawarangul K, et al. ${ }^{7}$ However, there were evidences that maternal smoking during pregnancy increased the risk of recurrent wheezing in the first few years of life..$^{15,18}$

Rhinovirus was found to be the most prevalent virus precipitating acute wheezing in hospitalized children with acute wheezing in our study. The finding was consistent with the previous reports. ${ }^{13,19,20}$

Prescription of controllers in our study was counted if inhaled corticosteroids or leukotriene receptor antagonist was prescribed from any hospital visits during follow-up period of 12 months. Prescription of inhaled corticosteroids and leukotriene receptor antagonist was not associated with recurrent wheeze during 12 months of follow-up in our study. There is an evidence from clinical trials that inhaled corticosteroids had beneficial effect on prevention of recurrent wheeze in preschool children, ${ }^{21}$ but not for leukotriene receptor antagonist. ${ }^{22}$ A course of inhaled steroids after acute bronchiolitis is not effective in preventing recurrent wheeze. ${ }^{23}$ Almost half of participants in our study admitted with the first wheezing episode, may suffered from acute bronchiolitis. According to a non-randomized control trial design of our study; there is a risk for bias to determine a treatment effect during follow-up. Indication and contraindication bias occurs because physicians normally prescribe controllers based on clinical findings and guidelines of individual hospital. Some participants were prescribed controllers after ER visits of recurrent wheeze while some of them might be prevented from recurrent wheeze by controllers prescribed earlier. Interpretation the effect of controllers in our study, therefore, should be cautious since causality and reverse causality bias mixed up the observed effect.

In conclusion, recurrent wheezing during 12 months of follow-up among preschool children who were admitted with acute wheezing was common. It is recommended to evaluate and followed preschool children with acute wheezing for a period, especially patients with the risk factors including the second born child or more, vitamin D insufficiency, "ever wheeze", and allergic rhinitis.

\section{Acknowledgement}

The study was funded by the Health Systems Research Institute (HSRI). We would like to acknowledge the Center of Excellence in Clinical Virology, Faculty of Medicine, Chulalongkorn 
University in supporting for viral study of nasopharyngeal specimens. We would like to appreciate for the cooperation of Bhumibol Adulyadej Hospital, King Chulalongkorn Memorial Hospital, Saraburi Hospital, Thammasat University Hospital and the Center of Excellence in Applied in Epidemiology, Thammasat University. The authors gratefully acknowledge the cooperation of the children and parents who have participated in this study.

\section{References}

1. Yunginger J, Reed CE, O'Connell EJ, Melton LJ, O'Fallon WM, Silverstein MD. A community-based study of the epidemiology of asthma. Incidence rates, 1964- 1983. Am Rev Respir Dis. 1992;146:888-94.

2. Strachan DP, Butland BK, Anderson HR. Incidence and prognosis of asthma and wheezing illness from early childhood to age 33 in a national British cohort. BMJ. 1996;312:1195-9.

3. Taussig LM, Wright AL, Holberg CJ, Halonen M, Morgan WJ, Martinez FD. Tucson Children's Respiratory Study: 1980 to present. J Allergy Clin Immunol. 2003;111(4):661-75.

4. Martinez FD, Wright AL, Taussig LM, Holberg CJ, Halonen M, Morgan WJ. Asthma and wheezing in the first six years of life. N Engl J Med. 1995;332:133-8.

5. Global Initiative for Asthma [Internet]. Fontana: Global Initiative for Asthma; c2019. Pocket Guide for Asthma Management and Prevention in Children 5 Years and Younger, updated April 2015 [cited 2019 May 1]; [about 1 screen]. Available from: https://ginasthma.org/pocket-guide-forasthma-management-and-prevention-in-children-5-years-and-younger/.

6. Morgan WJ, Stern DA, Sherrill DL, Guerra S, Holberg CJ, Guilbert TW, et al. Outcome of asthma and wheezing in the first 6 years of life: follow-up through adolescence. Am J Respir Crit Care Med. 2005;172:1253-8.

7. Chantawarangul K, Deerojanawong J, Sritippayawan S. First episode of preschool wheeze requiring hospitalization: a prospective study on the chance of recurrence and associated factors. Asian Pac J Allergy Immunol. 2018;36(4):232-7.

8. Teeratakulpisarn J, Pientong C, Ekalaksananan T, Ruangsiripiyakul $\mathrm{H}$, Uppala R. Rhinovirus infection in children hospitalized with acute bronchiolitis and its impact on subsequent wheezing or asthma: a comparison of etiologies. Asian Pac J Allergy Immunol. 2014;32(3):226-34.

9. Topal E, Bakirtas A, Yilmaz O, Ertoy Karagol IH, Arga M, Demirsoy MS, et al. Short-term follow-up of episodic wheeze and predictive factors for persistent wheeze. Allergy Asthma Proc. 2013;34(6):e42-6.
10. Tham EH, Lee AJ, Bever HV. Aeroallergen sensitization and allergic disease phenotypes in Asia. Asian Pac J Allergy Immunol. 2016;34(3):181-9.

11. Kulig M, Bergmann R, Tacke U, Wahn U, Guggenmoos-Holzmann I. Long-lasting sensitization to food during the first two years precedes allergic airway disease The MAS Study Group, Germany. Pediatr Allergy Immunol. 1998; 9:61-7.

12. Guilbert TW, Morgan WJ, Zeiger RS, Bacharier LB, Boehmer SJ, Krawiec $\mathrm{M}$, et al. Atopic characteristics of children with recurrent wheezing at high risk for the development of childhood asthma. J Allergy Clin Immunol. 2004;114(6):1282-7.

13. Guo J, Zhu W, Wang H, Holt PG, Zhang G, Liu C. Risk factors and prognosis of recurrent wheezing in Chinese young children: a prospective cohort study. Allergy Asthma Clin Immunol 2019;15:38.

14. Midulla F, Nicolai A, Ferrara M, Gentile F, Pierangeli A, Bonci E, et al Recurrent wheezing 36 months after bronchiolitis is associated with rhinovirus infections and blood eosinophilia. Acta Paediatr. 2014. 103(10):1094-9.

15. Sahiner UM, Buyuktiryaki B, Cavkaytar O, Arik Yılmaz E, Soyer O, Sackesen C, et al. Recurrent wheezing in the first three years of life: short-term prognosis and risk factors. J Asthma. 2013;50(4):370-5.

16. Brooks C, Pearce N, Douwes J. The hygiene hypothesis in allergy and asthma: an update. Curr Opin Allergy Clin Immunol. 2013;13(1):70-7.

17. Almqvist C, Olsson H, Fall T, Lundholm C. Sibship and risk of asthma in a total population: A disease comparative approach. J Allergy Clin Immunol. 2016;138(4):1219-22.

18. Duan C, Wang M, Ma X, Ding M, Yu H, Han Y. Association between maternal smoking during pregnancy and recurrent wheezing in infancy: evidence from a meta-analysis. Int J Clin Exp Med. 2015;8(5):6755-61.

19. Kieninger E, Regamey N. Rhinoviruses: markers of, or causative for, recurrent wheeze and asthma? Eur Respir J. 2012;39(2):238-9.

20. Rubner FJ, Jackson DJ, Evans MD, Gangnon RE, Tisler CJ, Pappas TE, et al. Early life rhinovirus wheezing, allergic sensitization, and asthma risk at adolescence. J Allergy Clin Immunol. 2017;139(2):501-7.

21. Castro-Rodriguez JA, Rodrigo GJ. Efficacy of inhaled corticosteroids in infants and preschoolers with recurrent wheezing and asthma: a systematic review with meta-analysis. Pediatrics. 2009;123(3):e519-25.

22. Hussein HR, Gupta A, Broughton S, Ruiz G, Brathwaite N, Bossley CJ. A meta-analysis of montelukast for recurrent wheeze in preschool children. Eur J Pediatr. 2017;176(7):963-9.

23. Green P, Aronoff SC, DelVecchio M. The Effects of inhaled steroids on recurrent wheeze after acute bronchiolitis: A systematic review and meta-analysis of 748 Patients. Glob Pediatr Health. 2015; 2: 2333794X 15595964 . 